\title{
Additive Construction with Mobile Emplacement: Multifaceted Planetary Construction Materials Development
}

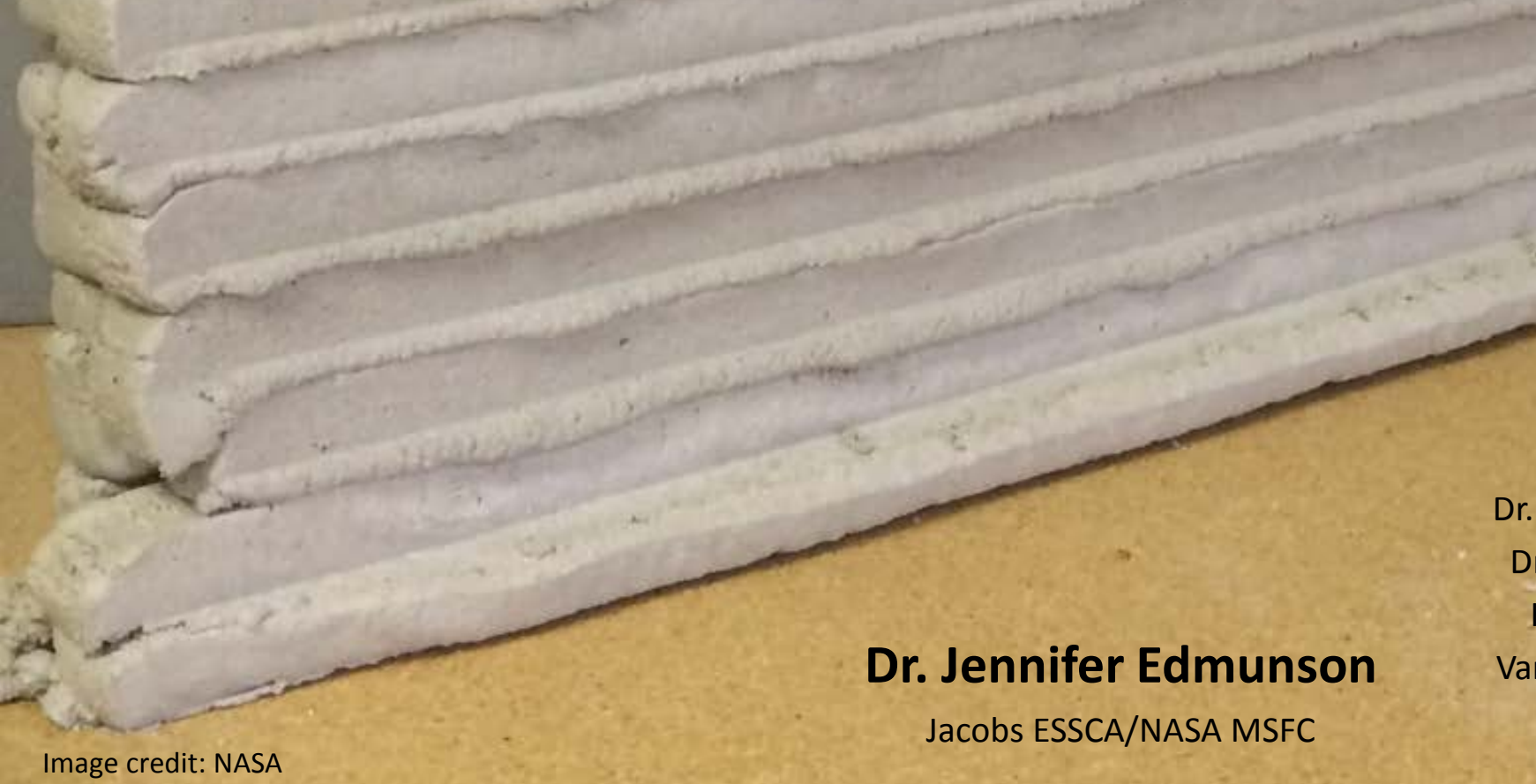

Image credit: NASA
Jacobs ESSCA/NASA MSFC
Mike Fiske - Jacobs ESSCA/NASA MSFC Rob Mueller - NASA KSC

Dr. Hunain Alkhateb - University of Mississippi Dr. Amin Akhnoukh - East Carolina University Heather Morris - Jacobs ESSCA/NASA MSFC Van Townsend - Craig Technologies/NASA KSC John Fikes - NASA MSFC Mallory Johnston - NASA MSFC 


\section{ACME: Background}

- Additive Construction

- "The process of joining materials to create constructions from 3D model data" (Labonnote et al., 2016)

- brick stacking, powder bed printing, and liquid/slurry/paste extrusion

- 3D models allow fabrication of multiple types of structures - roads, berms, habitats, garages, hangars, etc. - with a single device

- Original work at Marshall Space Flight Center (MSFC) 2004-2007

- Contour Crafting, goal of using resources found in-situ on planetary surfaces 


\section{ACME: Background}

- Interest from the United States Army Corps of Engineers (USACE) since 2014

- Use locally available cement/concrete

- Work captured, co-funded by USACE and NASA/STMD/GCDP* (2015-2017)

- Additive Construction with Mobile Emplacement (ACME)

- Delivery of Additive Construction of Expeditionary Structures (ACES) system

- Materials work

- Paste type preferred

- Little to no construction waste

- No mortar and adhesive used between bricks

- No formwork

- Single feedstock delivery and emplacement system

- Scalable 


\section{ACME: Background - MSFC ACME-2}

Gantry Mobility

System

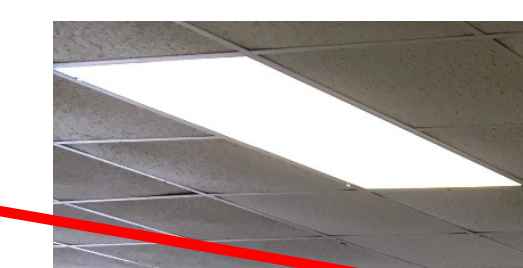

Mixer

Accumulator

(allows pump to stay on when nozzle closes for doors/windows)

Hose

- ACME - Constraints - Methodology

- $\quad$ Results

- $\quad$ Next Steps 


\section{ACME: Material Constraints}

- Must be compatible with additive construction technologies

- Capable of being extruded, stacked, or emplaced layer by layer - predictably

- Avoid warping and shrinkage during cooling/curing

- Capable of being removed for system cleaning easily (or avoid cleaning by using a material such as thermoplastics)

- Capable of being pumped or moved through the system without easily damaging, clogging, or abrading system components

- Vibration

- Capable of mixing adequately and predictably

- Accurate dispensing and mixing ratios

- Capable of pressurization if pumped

- Consistency of a mix-specific viscosity 


\section{ACME: Material Constraints}

- Must be composed of in-situ resources (reduce/eliminate cost of launching construction material)

- Resources are site-specific, must know what materials are available (and have adequate simulants)

- LARGE quantity of (processed) feedstock is needed

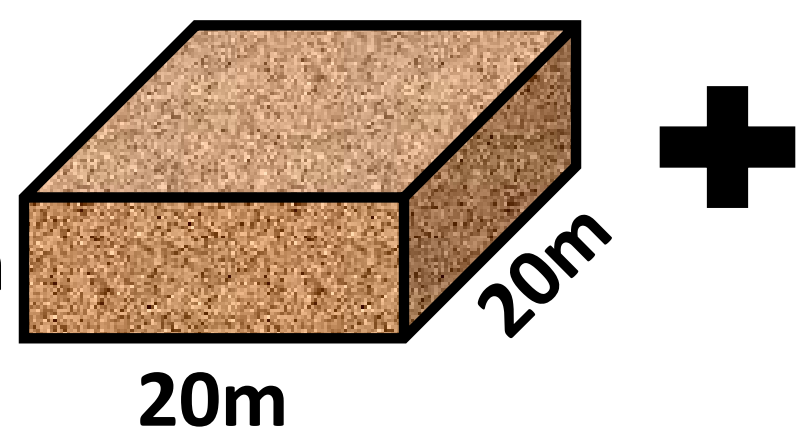

$0.2 \mathrm{~m}$ wall thickness
$40 \mathrm{~m}^{3}$ construction material (not including foundation or roof) 


\section{ACME: Material Constraints}

- Must be composed of in-situ resources

- Minimize the use of water

- Minimize the potential for deleterious chemical reactions

- Geology varies on small scales

- Mechanical binder for regolith grains is preferred (does not have to be a "precise mix")

- Minimize the energy needed to mine the material

- Use loose surface regolith when possible

- The original composition dictates:

- Viscosity at given temperatures

- Extrudability / workability of the mixture

- Initial compressive strength, support subsequent layers

- Initial set time

- Layer adhesion

- Resistance to aging (degradation over time) 


\section{ACME: Material Constraints}

- Must be compatible with (extreme) planetary surface environments

- Deposition

- Gravity

- Pressure at the surface

- Deposition and Aging

- Temperature swings

- Thermal expansion

- Aging

- Radiation (galactic cosmic rays, solar particle events)

- Solar wind

- Micrometeorite bombardment 


\section{ACME: Material Constraints}

- Ability to provide necessary structural integrity

- Strength of the material (all aspects)

- Define accurate construction tolerances for thermal expansion and vapor loss

- Layer adhesion

- Durability in the environment

- Compatibility with human activities - must not be flammable, decompose, or become toxic when exposed to $\mathrm{H}_{2} \mathrm{O}, \mathrm{O}_{2}$, or $\mathrm{CO}_{2}$ (unless lined) 


\section{ACME: Methodology}

- Multiple materials are under study as planetary construction materials by multiple groups

- ACME materials research

- Kennedy Space Center - focus on minimally processed regolith

- Sintering

- Polymer/regolith simulant mixtures (polymer to be created from the $\mathrm{CO}_{2}$-rich atmosphere of Mars)

- Marshall Space Flight Center - focus on cementitious materials similar to USACE

- Planetary regolith simulant as aggregate

- Binders such as Ordinary Portland Cement, MgO-based cements, and sodium silicate

- Previous work with sulfur, polyethylene, and sintering 


\section{ACME: Methodology - MSFC}

- Standard mixture

- Ordinary Portland Cement (OPC)

- Water

- Navitas (rheology control)

- Stucco mix (includes sand)
- Simulant mixture

- OPC

- Water

- Navitas

- Simulant (JSC Mars-1A)

- Stucco mix (includes sand)

All aggregate used was less than $64 \mathrm{~mm}$ in size. Mixes captured above were used for printing. Other mixtures were compression tested. 


\section{ACME: Methodology - MSFC}

- Standard mixture defined viscosity for the ACME-2 additive construction system (between 5 and 20 Pa*s for OPC-based material)

- Pump-able mixture

- Retain cohesiveness

- Smooth extruded bead

- MgO-based binder also investigated but not utilized in the ACME-2 system

- Required constant vibration not possible in the ACME-2 feedstock delivery system

- QUICK set-up time 


\section{ACME: Results to Date - MSFC}

- Three samples were cast into $15.24 \mathrm{~cm} \times 15.24 \mathrm{~cm} \mathrm{x}$ $2.54 \mathrm{~cm}$ molds, one was 3D printed with Mars simulant aggregate
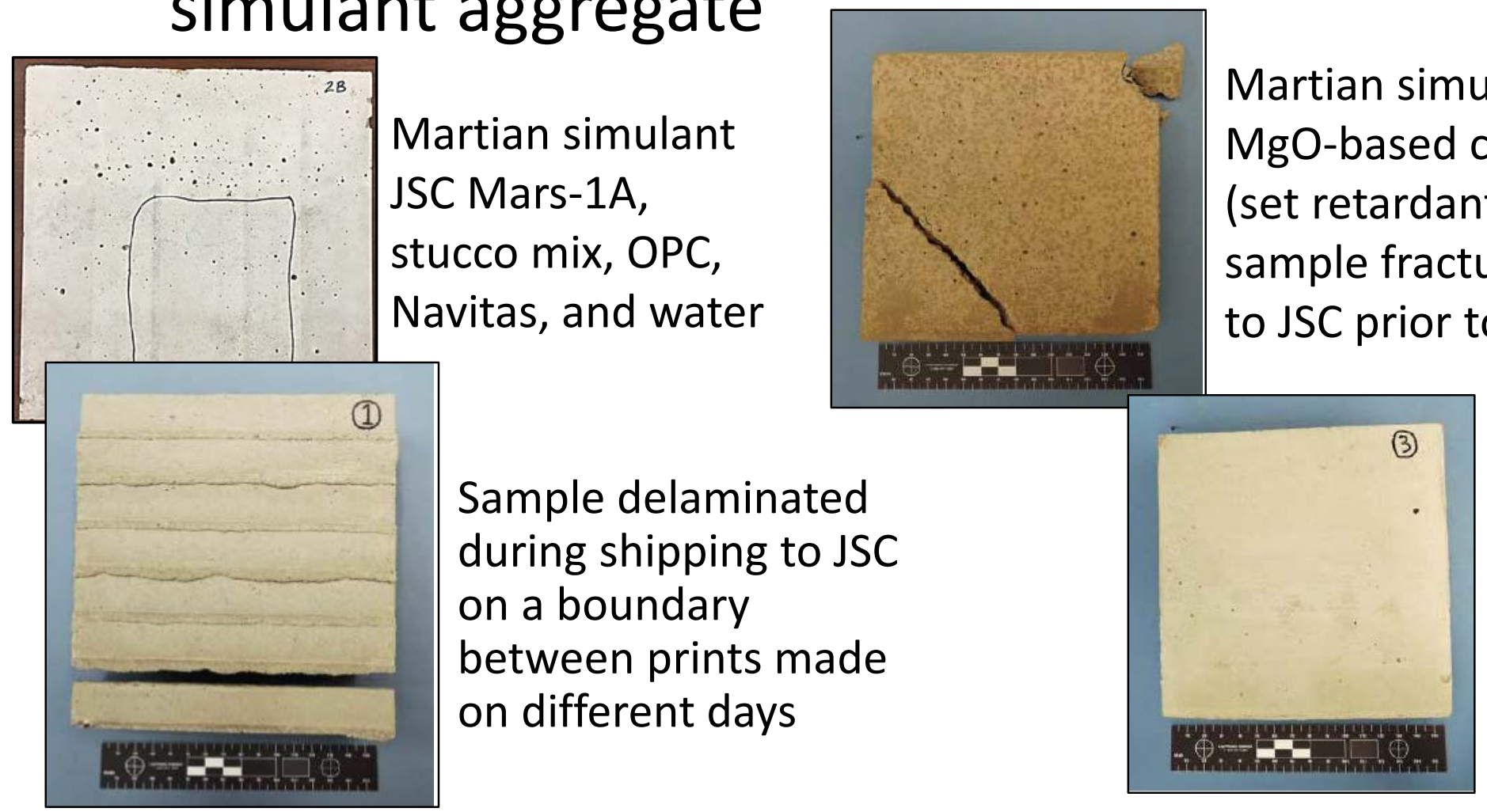

Lunar simulant Sample delaminated during shipping to JSC on a boundary between prints made on different days

JSC-1A, stucco mix, OPC, Navitas, and water 


\section{ACME: Results to Date - MSFC}

- Hypervelocity impact tests were internally funded and performed at the White Sands Test Facility in Las Cruces, NM

- $2.0 \mathrm{~mm}$ Al 2017-T4 (density $2.796 \mathrm{~g} / \mathrm{cm}^{3}$ ) impactor, 0.17caliber light gas gun, $0^{\circ}$ impact angle, 1 Torr $\mathrm{N}_{2}$ in chamber during test

- $7.0 \pm 0.2 \mathrm{~km} / \mathrm{s}$ velocity (approximate mean expected velocity of micrometeorites at the surface of Mars, and higher than expected velocity for bullets on Earth)

- Kinetic energy is equivalent to a micrometeorite with a density of $1 \mathrm{~g} / \mathrm{cm}^{3}$ and a diameter of $0.1 \mathrm{~mm}$ traveling at a velocity of $10.36 \mathrm{~km} / \mathrm{s}$, as well as a $9 \times 17 \mathrm{~mm}$ Browning Short bullet. 


\section{ACME: Results to Date - MSFC}

- Image scales are comparable
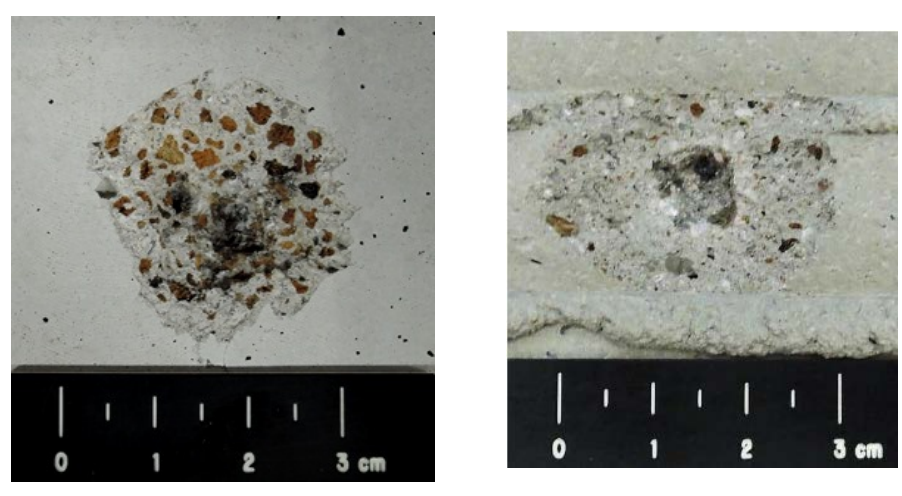

Martian simulant JSC Mars-1A, stucco mix, OPC, Navitas, and water

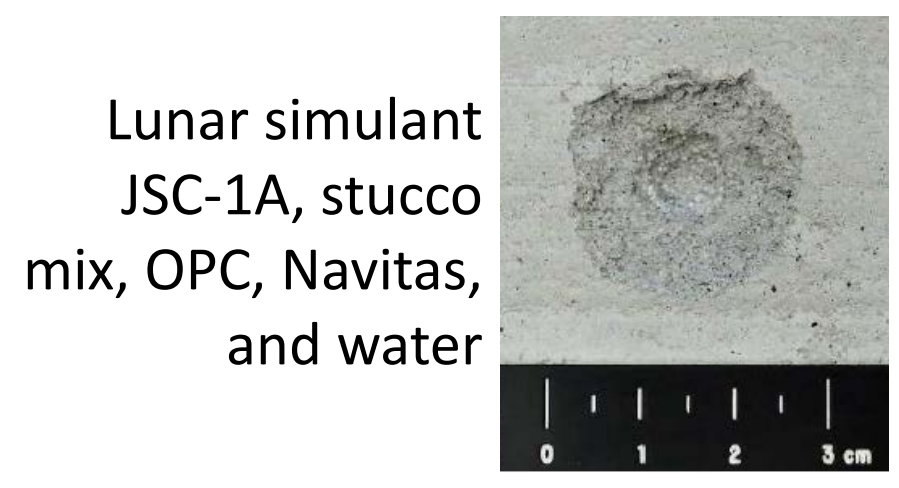

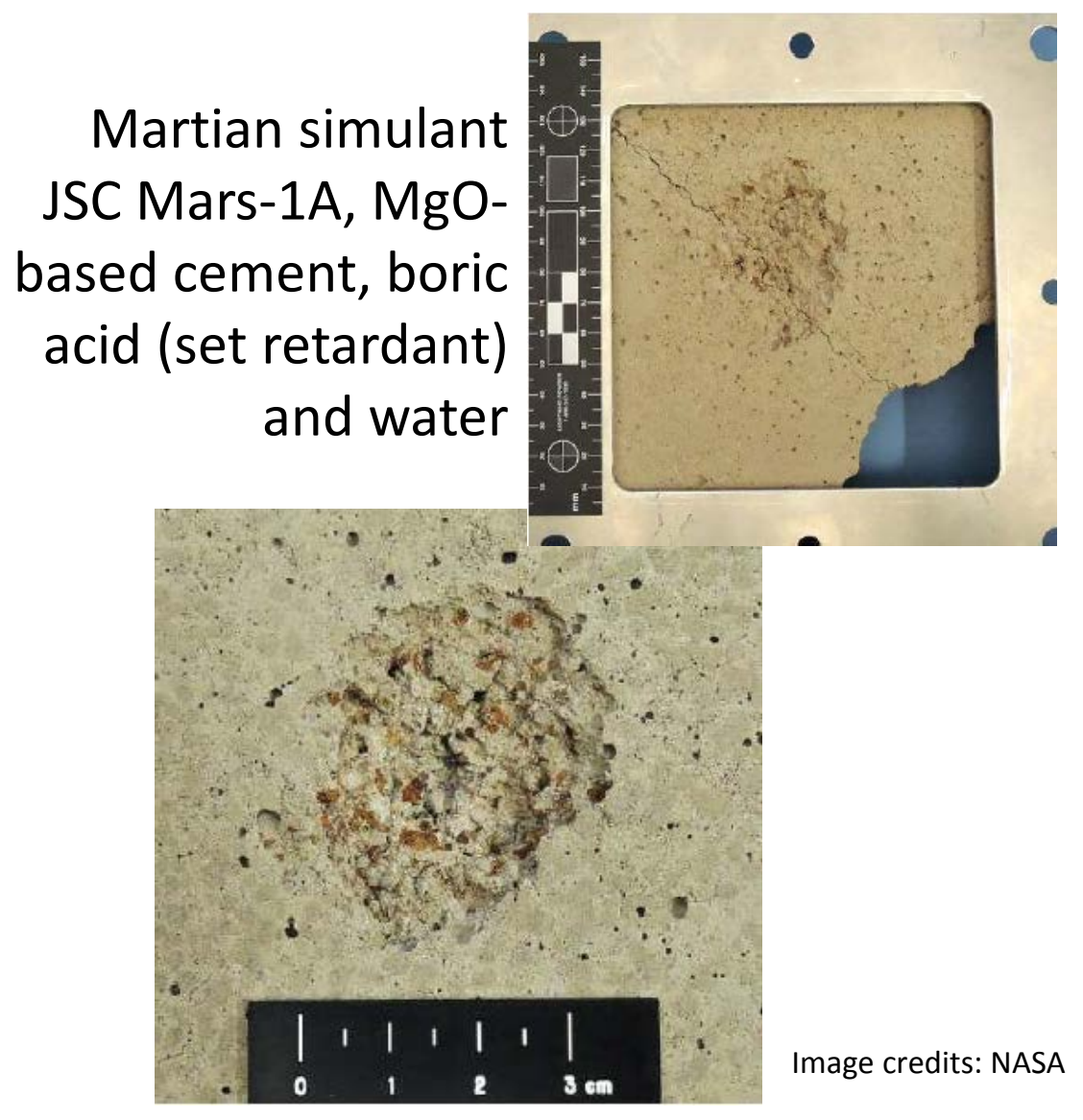




\section{ACME: Results to Date - MSFC}

- Hypervelocity Impact Testing conclusions (Ordonez et al., 2017)

- MgO-based cement, in this formulation, is not as resistant to impact as OPC

- The projectile did not penetrate as deeply into the JSC-1A simulant-based mortar (compared to the JSC Mars-1A simulant-based mortar)

- Smaller grain size of JSC-1A simulant

- Makeup of JSC-1A simulant (grains not as porous as JSC Mars-1A simulant, crushed basalt versus weathered ash)

- More deleterious reactions in the JSC Mars-1A mortar?

- Layer adhesion issue 


\section{ACME: Results to Date - MSFC}

- Grain size analysis/OPC binder - compression testing

- Standard $5.08 \mathrm{~cm}$ cubes, 7 and 28 days

- Initial strength related to tricalcium silicate formation

- Ultimate strength related to dicalcium silicate formation

\begin{tabular}{lcccc}
\hline Size Fraction $(\mu \mathrm{m})$ & \multicolumn{2}{c}{ JSC Mars-1A $(\mathrm{kPa})$} & \multicolumn{2}{c}{$J S C-1 \mathrm{~A}(\mathrm{kPa})$} \\
& 7-Day & 28-Day & 7-Day & 28-Day \\
\hline $4000-5000$ & 20339 & 32218 & & \\
$2000-3999$ & 21146 & 35584 & & \\
$1000-1999$ & 22111 & 32675 & & \\
$500-999$ & 21335 & 33515 & 20554 & 28244 \\
$250-499$ & 21949 & 35633 & 24728 & 34158 \\
$125-249$ & 25628 & 31905 & 21089 & 26170 \\
$63-124$ & 27802 & 34326 & 27820 & 37098 \\
$<63$ & 23939 & 29967 & 29367 & 37140 \\
Unsieved & 22826 & 24383 & 27796 & 36092 \\
\hline
\end{tabular}

- Tensile properties not measured but expected to be $\sim 10 \%$ of compression results 


\section{ACME: Results to Date - MSFC}

- One more thing...

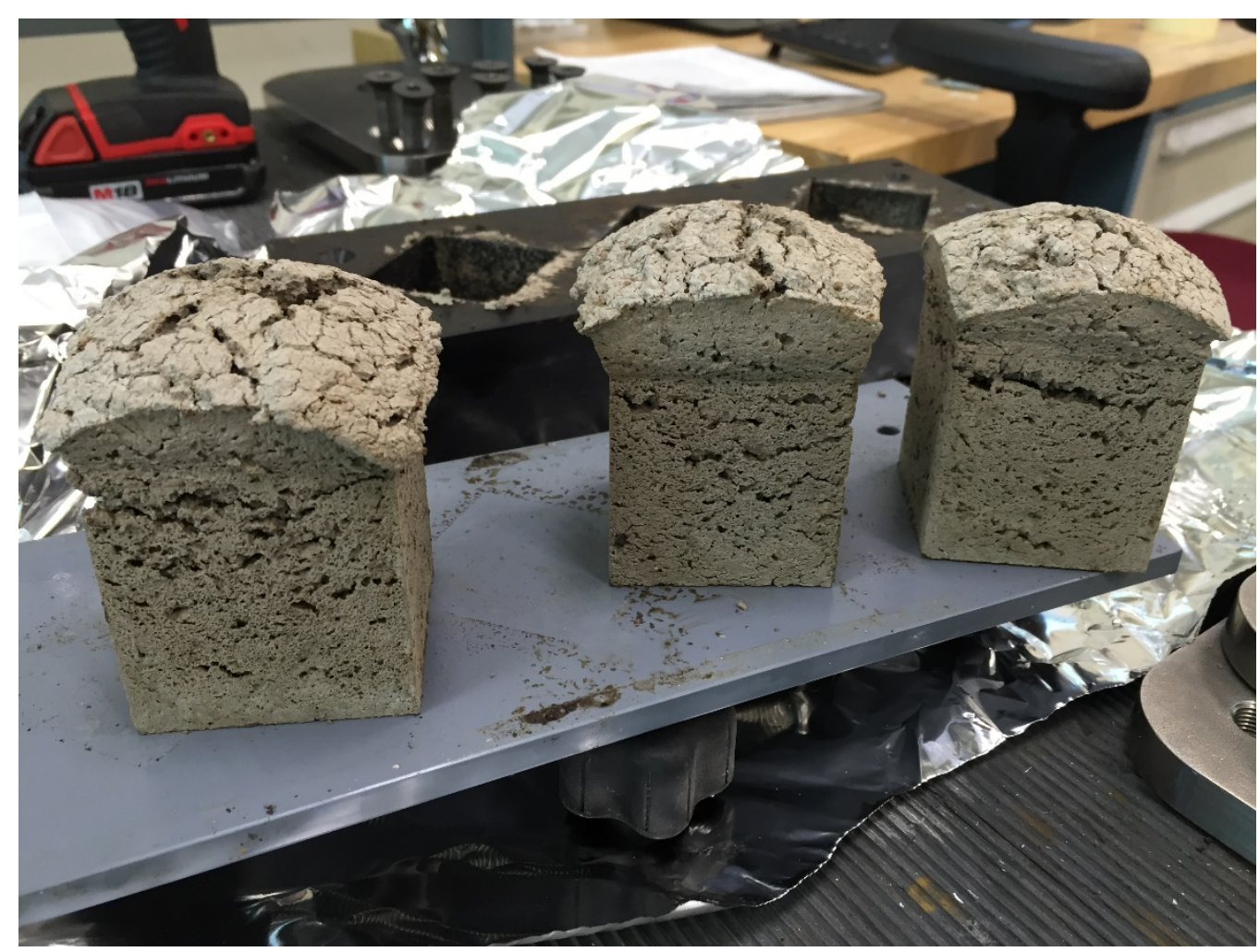




\section{ACME: Next Steps}

- Investigate and characterize more binders

- Target specific proposed landing sites, generate (as accurately as possible) simulants, and mature binder fabrication and emplacement technologies

- Test them in replicated environments

- Thermal cycling, vacuum curing, etc.

- Establish building codes for planetary structures, and standards for additively constructed materials

- Set up an artificial neural network to help optimize these multifaceted, multifunctional materials

- Balance between the site-specific regolith composition, extreme environments, emplacement via additive technologies, and characteristics of the final structure 


\section{ACME: Next Steps}

- Optimization through trade studies / artificial neural network

- Grain size

- Compressive strength (including regolith load)

- Tensile strength

- Thermal conductivity

- Radiation protection (materials and/or regolith shell)

- Need for a skin/liner (pressurized?)

- Cost to produce

- Time to produce

- Aging

- Ability to be repaired

- Ability to cure in a specific planetary environment 


\section{https://www.bradley.edu/sites/challenge/}

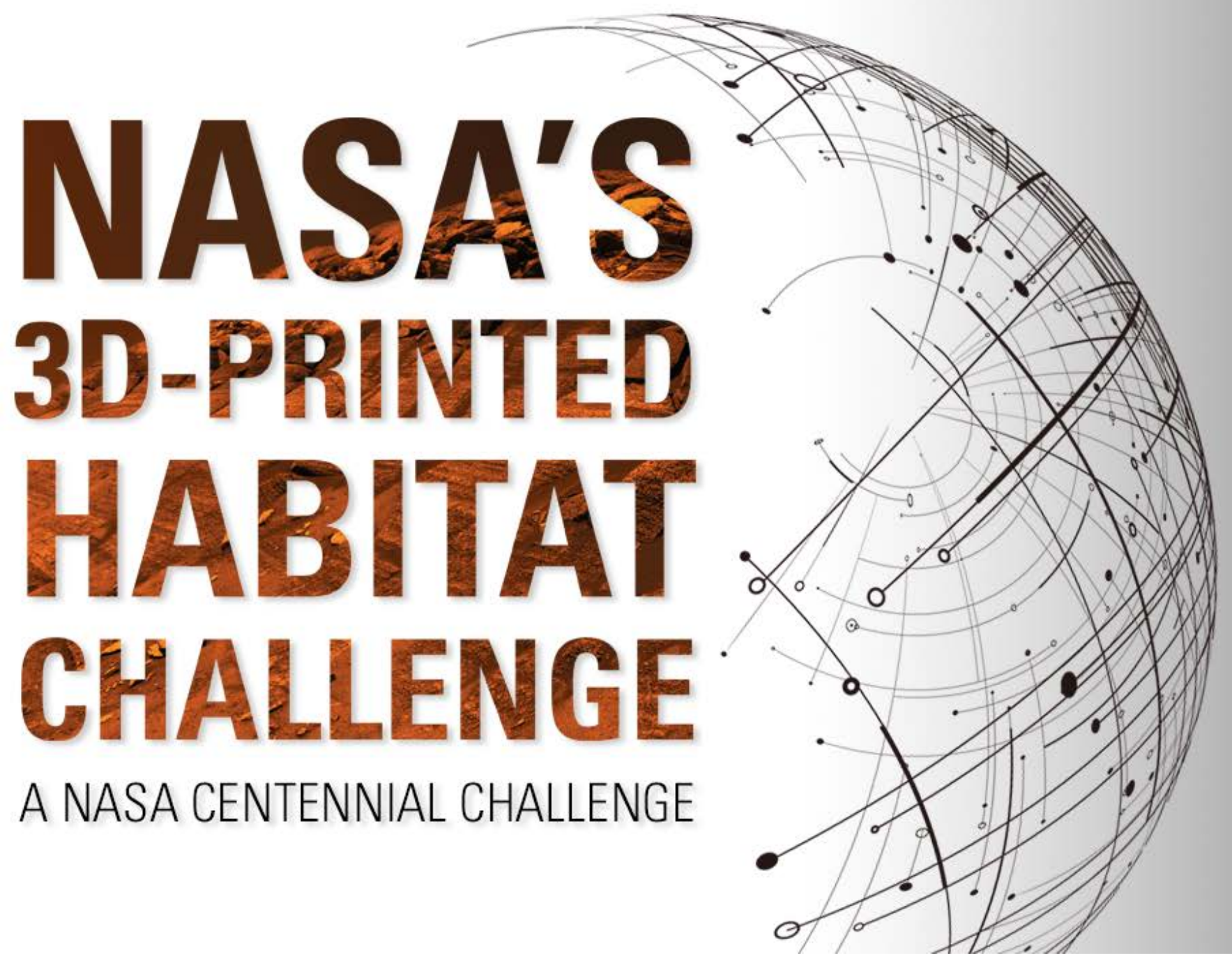




\section{References and Acronyms}

Labonnote, N., Ronnquist, A., Manum, B., Ruther, P. (2016) "Additive construction: State-of-the-art, challenges and opportunities". Automation in Construction, 72(3), 347-366.

Ordonez, E., Edmunson, J., Fiske, M., Christiansen, E., Miller, J., Davis, B., Read, J., Johnston, M., and Fikes, J. (2017) "Hypervelocity impact testing of materials for additive construction: Applications on Earth, the Moon, and Mars". Procedia Engineering, 204, 390-396.

3D - Three-dimensional

ACES - Additive Construction of Expeditionary Structures

ACME - Additive Construction with Mobile Emplacement

ESSCA - Engineering Services and Science Capability Augmentation (contract)

GCDP - Game Changing Development Program

JSC - Johnson Space Center

KSC - Kennedy Space Center

MSFC - Marshall Space Flight Center

NASA - National Aeronautics and Space Administration

OPC - Ordinary Portland Cement

STMD - Space Technology Mission Directorate

USACE - United States Army Corps of Engineers 